\title{
Distribution Shop Center (Distro) Local Brand Clothes and Skate Playges in Kuta Utara, Badung, Bali
}

\author{
N Rara Ranubhuana ${ }^{1}$, I Made Adhika ${ }^{2}$, I Gusti Bagus Budjana ${ }^{3}$ \\ Bachelor Degree of Architecture Study Program \\ Faculty of Engineering-Udayana University \\ Jimbaran \\ ranubhuana@gmail.com \\ Architecture Study Program \\ Faculty of Engineering-Udayana University \\ Jimbaran \\ Architecture Study Program \\ Faculty of Engineering-Udayana University \\ Jimbaran
}

\begin{abstract}
The centre of clothing distro and skatepark are buildings that are included in commercial and business functions. The centre of clothing distro is community of several clothing brands that have their own distro. The function of distro is to display and sell their products. Various concepts and idealism are offer from every clothing brands. Some concepts are offer such as music, skateboarding, custom motorbikes, surfing, tropics, and other concepts. The concepts of the brand will affect the interior concept that will applicated. The goal is to provide the identity and characteristics of distro, so that attract consumers to come and buy some products. The industrial concept interior is very suitable to be apply in a dis-tro. The material in industrial concept shows natural impression of material such as expose bricks, concrete, floor and some finishing marerials while still displaying the original texture. This makes the industrial concepts more affordable but requires high creativity, so that it is suitable to be apply in a distro. This concept will give a masculine impression, rough but still comfortable. The collaboration of the industrial concept with the concept with the concept of clothing brand can be apply by adding some decoration and artwork that related with the concept.
\end{abstract}

Index Terms - industrial, distro, interior.

\section{INTRODUCTION}

Clothing distribution stores (distros) are stores that sell clothing to end consumers to meet personal needs and are not for sale anymore. The product sold can be in the form of a shop's own clothing brand or another brand that entrusts the product to the store. Bali as a very famous tourism region has caused the distribution of local brands not to develop rapidly compared to foreign brands. Foreign brand distributions are highly developed with spacious and magnificent buildings. The products sold are also very complete and varied. Very different from the local distribution which is only a small rental shop with several displays in it. Local brand clothing distribution center (distro) and skate park in North Kuta, Badung is a shopping center facility which consists of several local brand clothing distributions as its main function. This facility does not only have a skate park as a supporting facility. Some supporting facilities available such as entertainment facilities, culinary activities, musical performances and exhibitions. Distro and skatepark certainly have a mutually beneficial relationship. Vendors or owners of a clothing brand can recognize skateboarders 
who can be sponsored and skateboarders can help promote their products (Ranubhuana, 2018: 59).

Distro as the main activity facility serves to showcase and sell products from a clothing brand. Each clothing brand certainly has a certain concept that is used as an identity. Usually the concept already has its own market or consumer. For example clothing brands with music concepts are in high demand by the music community, extreme sports concepts are highly in demand by the skateboarding, surfing and BMX communities. Each distro in the local brand clothing distribution center will certainly compete with each other in attracting buyers. To maintain the competitiveness of a distribution, it is necessary to have a unique interior design while remaining comfortable and functional. Interior design is also able to display a variety of distinctive features of the distro[1]. One unique interior concept is the industrial interior concept. The application of the industrial concept is quite affordable because the selection of materials in the industrial concept displays the impression of what it is for example exposed bricks, concrete floors and some finished materials while still emphasizing its original texture. This interior design concept can also be collaborated with concepts that are carried by clothing brands. The interior design goals of a dis-tro not only increase the attractiveness of a distro but must also consider safety both for people with disabilities, children and the elderly.

A good interior design and appropriate for its design can encourage the arrival of consumers and increase the opportunity to sell several products[2]. This research was conducted to find out the application of industrial concepts in the intrerior of one of the existing distributions at a local brand clothing distribution center (distro) and a skate park in Kuta Utara, Badung, Bali. The method used is descriptive qualitative and analysis by comparing the existing literature.

\section{RESUlt AND ANALISYS}

\section{A. Industrial Interior Concepts}

Industrial-style designs originally appeared in Europe. This interior and architectural design began to develop because of the many factory buildings that are no longer in operation. The factory building was finally converted into a decent and comfortable residence by making a few adjustments. Some changes and adjustments were made but still did not eliminate the original character of the factory building. Interior design is the design of the layout and space in buildings (Ching, 2000: 46). So the industrial interior concept is the design of the layout of the inner space by applying adjustments to a space and then refining it without removing the characteristics of the space. This concept certainly gives the impression of being masculine and a little rough because it was adapted from an industrial factory, but still provides comfort and safety. The application of industrial concepts in the interior of a distribution can be seen from the elements of the room compilers, the lighting or lighting settings and the decoration or artwork used.

\section{B. Lay Out Distro}

Layout distributions must have been designed in accordance with the planned space program. As for some distribution areas in the distribution, namely the area for product display (selling space), the area of storage of goods (merchandise space), a special area of employees (personnel space) and the area for visitors (customer space). The layout layout of the distribution with more detailed area division is shown in Figure 1 below.

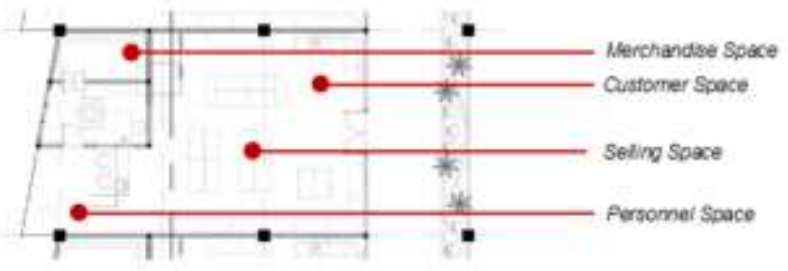

Fig. 1. Lay Out Distro (source: Ranubhuana)

The important thing in designing store layout is circulation patterns. In the distro layout within the local brand clothing distribution center uses a geometric circulation pattern. Geometric circulation patterns are very precisely applied in a distribution. The advantage of this circulation pattern it can streamline space so that it can allocate more space for product display [3]. For visitors with this circulation circulation, the shopping process will certainly run faster. This geometric circulation pattern will make it easy for distro owners to control the security of existing inventory in selling space.

\section{Elements of Space}

Basically the constituent elements of space are divided into three elements namely the bottom element (floor), the side element (wall) and the upper element (ceiling). The choice of material in the constituent elements of space will be the basis of the success of the application of the industrial interior concept. The application of industrial concepts certainly influences the choice of material in order to create the impression of masculine, rude but still providing comfort and of course affordable. For more details, see Figure 2 below. 


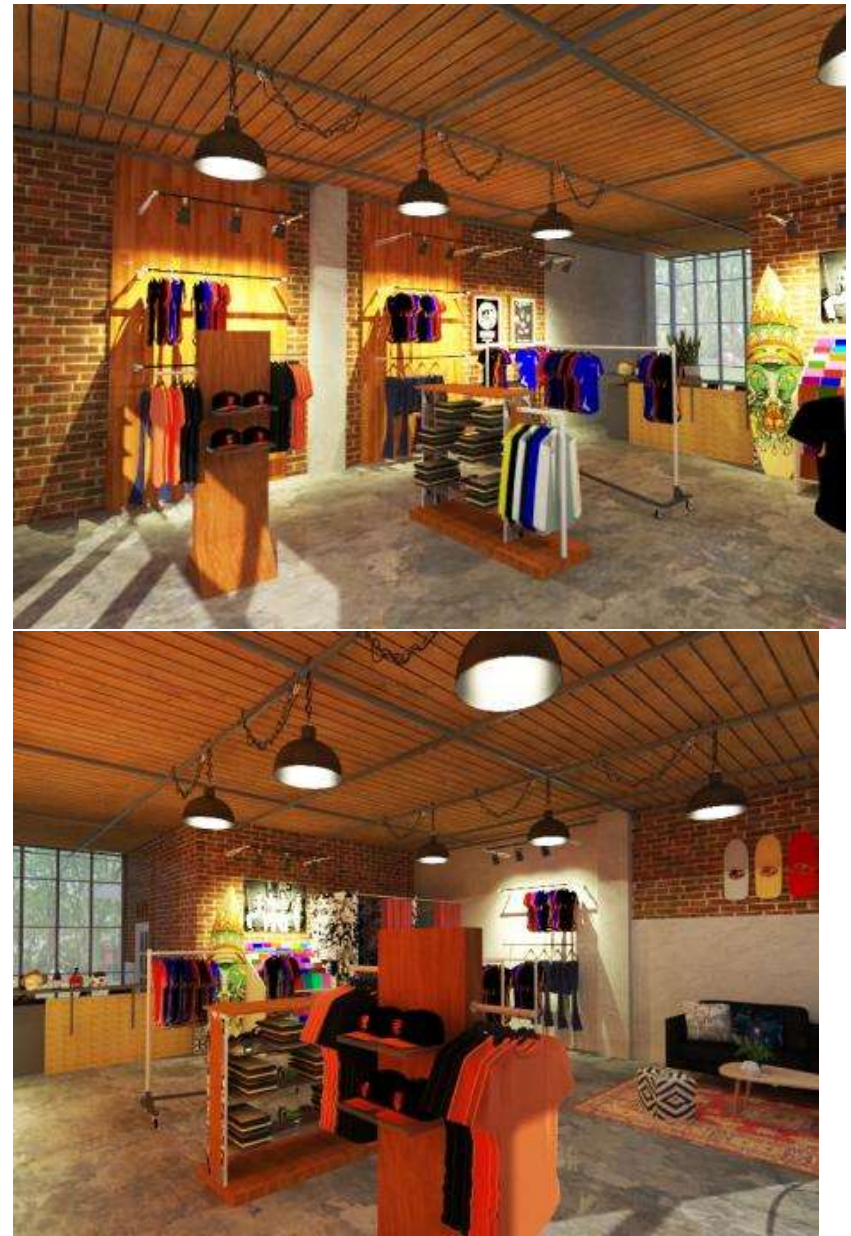

Fig. 2. Interior Design for Distro (source: Ranubhuana)

Industrial concept applications usually use materials that tend to be monochromatic or maintain the original color of the material. Impression of imperfection or unfinishing will be its own characteristic in the interior of the distribution. The selection of basic elements in the industrial interior concept usually uses polished concrete floors or parquet and does not use ceramic or granite. On the basic elements or distro floor using a concrete floor with a finishing that is smoother but not too shiny. The application of concrete material on the distribution will give the impression of coolness in the room due to the color and nature that resembles a stone. Polished concrete floors will cause patterns that are not patterned, dynamic and of course very unique on the distribution floor. Side elements in the distro's interior design use 2 main materials, exposed bricks and white paint finishing campers. The natural color of the bricks will give a warm impression to the room. Wider impression will be felt in the room because of the visual bricks are small with a tight installation. White kamprot plaster material is applied to each column on the distribution. White kamprot plaster is also applied to several parts of the wall so that the application of the stones does not look monotonous. The application of a protective plaster on the wall will give the

impression of a cleaner room. On the wall there are also several frames made of aluminum and parquet wood accents on the display attached to the wall. The upper element in the distribution design combines wood and iron metal materials. The ceiling lumber material will cover the top element. The absorption of wood material with a clear finish will look natural but not perishable (Andrie and Sriti, 2013). Installation of iron poles seems to be a ceillig lumber hitcher and a place to hang lights and electrical installations. The combination of wood and iron materials will certainly provide a unique and very attractive visualization of the distro's interior design.

\section{Lighting}

lighting is very important in the interior design of the distro. Placement and good lighting colors can certainly increase the selling value of a product. The main function of the distribution for product display will make the many uses of spotlight to support display lighting. In the application of industrial concepts, of course the selection of types, shapes and materials supporting the lamp becomes very important to support the material making up the space elements. The lighting color of the lamp is also very decisive in forming the atmosphere inside the distro. For more details, see Figure 3.

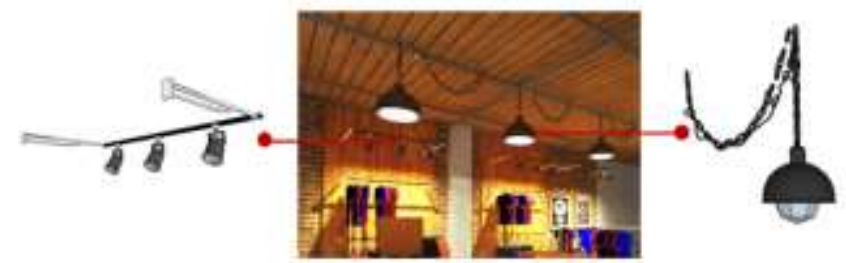

Fig. 3. Lighting (source: Ranubhuana)

In the interior design, the distro uses two types of downlights for main lighting and spotlight for product display lighting. Hanging lamps were chosen for downlights and halogen lamps mounted on clothes hangers became spotlights. Both of these lights are predominantly made of metal and are very unique. To present the impression of a more masculine lighting color selection using light orange.

\section{E. Decoration and Artwork}

A decoration and artwork can be added to add aesthetics to the interior design. Artwork is also able to show the identity of a clothing brand. Decoration and artwork are added to the elements of the floor, wall or ceiling. The use of decoration or artwork should not be excessive and as much as possible has a certain function. Display items to be sold can also be used as art work. Some of the artwork and decorations that are applied can be seen in Figure 4.

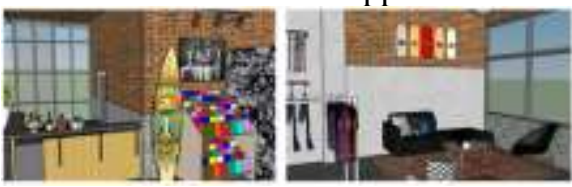

Fig. 4. Decoration (source: Ranubhuana)

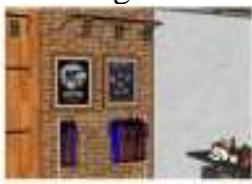

S. 
Journal of A Sustainable Global South, p-ISSN: 2579-6062

\section{CONCLUSION}

Based on an analysis of several elements that make up the appearance of the distro's interior design. It was concluded that the distro's interior design had been able to apply the concept of industrial design. The monochromatic color selection and natural characteristics can be seen in the interior design of the distribution. The industrial concept can easily be integrated with the concept of clothing brands. This concludes that the industrial concept that started from factory function change into a residential area can be applied to building business functions. The industrial interior concept which gives the impression of masculine and rough is certainly very appropriate to be combined with the concept of anti-mainstream and favored by men such as music and skateboarding. This masculine impression is the lack of this concept considering the facility users are not only from men. Therefore, very high creativity in designing and sensitivity in choosing a very diverse material is needed in industrial interior design.

\section{REFERENCES}

[1] Kusumowidagdo, "Peran Penting Perancangan Interior pada Store Based Retail", 2005.

[2] Levy, Michael \& Weitz B., "Retailling Management", New York : Mc Graw Hill, 1998.

[3] Barr, Vilma \& C. E. Broudy, "Designing To Sell”, 1984. 